\begin{tabular}{ccc}
\hline International Journal of Engineering \& Technology, $7(4.38)(2018) 1319-1322$ \\
SPC \\
Website: www.sciencepubco.com/index.php/IJET \\
Research paper
\end{tabular}

\title{
Construction of Attitude Towards Punctuality Scale for Univer- sity Students and Relationships to CSE and FTP
}

\author{
Duangduen Bhanthumnavina $\square$, Duchduen Bhanthumnavinb and Bung-On Sorodc \\ abThe Graduate School of Social and Environmental Development \\ cThe Graduate School of Human Resource Development \\ National Institute of Development Administration, Bangkok 10240, Thailand
}

\begin{abstract}
Time is essential in the modern industrial-technology society. In order to enhance time management skills in university students, Attitude toward punctuality Scale (ATP) was constructed. There were four studies with the total sample of 1,325 university students in Thailand. Eighty-three items were constructed, but only 36 items were selected by a group of experts. A six lunit rating scale accompanied each of the item, ranging from 1 "not true at all" to 6 "extremely true". In study1 with 200 students, 31 out of 36 items met the criteria for item quality. Results from EFA in study 2 using new 500 students revealed a three-factor model (5 items for cognitive aspect, 4 items for behavioral intention aspect, and 3 items for affective aspect) with the total of 12 items and $59.303 \%$ of the total variance accounted for. In study 3 using another 300 students, this model was confirmed by CFA. In study 4 using 225 students, it was found that CSE and FTP were positively and significantly related to the newly constructed ATP $(r=.357$ and .256 , respectively). Furthermore, ATP could predict punctual behavior beyond CSE and FTP for $26.500 \%$ with the total of $38.40 \%$. The importance of ATP was discussed. Future experimental studies, as well as, possible intervention programs are suggested.
\end{abstract}

Keywords: Attitude Towards Punctuality (ATP), University Students, Core Self-Evaluation (CSE), Future time perspective (FTP), Factor Analysis.

\section{Introduction}

Punctuality is becoming a necessity in modern living. However, in many societies, the success in time management has to be inculcated in younger generations. While older people can be left to their own choice and habit. Schools and universities are expected to be responsible for inducing appropriate attitude and behavior.

Punctual behavior of a person can be considered as one of the important mechanisms for avoiding failure to self, as well as, for guaranteeing success in work and life. Valid and reliable measures are the prerequisite for successful research and effective interventions.

This research article aims at reporting the construction process and preliminary validation of attitude towards punctual (ATP) scale for use with university students.

Youngsters attending educational institutions to acquire academic knowledge in various fields, can lead to their formation and change of attitude and intention, such as in entrepreneurial education 1-2 and in other areas. It has been widely accepted for a long time ago that education in various disciplines can do better in changing attitudes by giving more knowledge and correcting beliefs. Therefore, desirable attitudes can result from knowledge and education 3

K-A-P model predicts that specific educational program can lead to knowledge, attitudes, and finally to practice or targeted behavior as reported recently from Indonesia4

In order for higher education to enhance punctual attitude, and hopefully can lead to action or punctual habit, an attitude scale was constructed Thirty-six items were written in the context of academic environment of students, such as, being on time to class, meeting deadline for assignments, and being punctual for appointments with friends. It is hypothesized that the attitude and behavior scores are positively related in Thai students.

Even though, attitudes have been found to be closely related to behavior in the same context5, many other factors can still influence punctual behavior, such as other psychological traits of the actors.

Two important psychological traits which have been expected to relate to (or influence) work behavior, AID avoidance behavior, as well as student's behavior, are present- time perspective (FTP)6, core self-evaluation (CSE)7-8, and other personality and intelligence9-11.

Nevertheless, in some specific work context, research results led to the acceptance of situational influence with the downplay of personal traits12. Incremental validity of the attitude towards punctuality (ATP) is the main objective in this study. It is hypothesized that CSE and FTP are positively related to punctual behavior. More importantly, the ATP score can predict punctual behavior score beyond the amount of prediction of the CSE and FTP scores in the sample of upper-class Thai university students. This type of hypothesis is based on the recommend-dation from Cronback and Gleserin 13 as reemphasized in Smith, Fischer and Fister14

\section{Research Method}

The total of 1,325 upper-class university students participated in these 4-step studies as follows. For study 1, item quality of PBS was computed using data from 200 university students. Selected items were proceeded further to study 2 for exploratory factor analysis (EFA) using data from 500 university students. The 
measurement model from study 2 was confirmed by performing second-order confirmatory factor analysis (CFA) in study 3 . The last group of 225 university students was used in validation of the ATP.

\section{Results and Discussion}

\subsection{Study 1: Item Quality}

Two statistical approaches were used to consider item quality for ATP. First was item discrimination (t-ratio) which should be more than 1.96 (significant level at .05) 15-16. Second is item-total correlation ( $\mathrm{r}$ correlation) which should be at least 0.200 with significance. After item analysis using data from 200 university students, 31 of 36 items were selected (only 5 items were excluded from various parts of the ATP definition.

\subsection{Study 2: Exploratory Factor Analysis}

The 31 selected items were used in exploratory factor analysis (EFA) Three indicators17 were as follows: 1)Kaiser-Meyer-Olkin Measure of sample adequacy (KMO) should be at least 0.600 2) chi-square must be significant and 3) Eigenvalue of each dimension must be at least 1.000 .

Data from 500 university students, after performing EFA revealed threefactor model $(\mathrm{KMO}=0.891, \square 2=1965.336$, p-value $=.000, \mathrm{df}=66)$. The first factor consisted of 5 items. Three of the 5 items were cognitive aspect with the eigenvalue of 4.848. These five items could explain this construct with $40.404 \%$. The second factor consisted of 4 items. Two of which were behavioral intention aspect with the eigenvalue of 1.247. These four items added the predictive power of $10.395 \%$, resulted to the total predictive power of $50.799 \%$. The third factor consisted of 3 items. Two of which were affective aspect with the eigenvalue of 1.021. These three items had the predictive power of $8.505 \%$, resulted to the total predictive power of $59.303 \%$. The total of ATP was 12 items. Thus, the new ATP scale contained all of the original components of attitude.

\subsection{Study 3: Confirmatory Factor Analysis}

Another new 300 data from university student were used in second-order confirmatory factor analysis. There were four criteria17 in this step for a measure with number of items between 12-30 items and samples size more than 250, as follows: 1) chi-square should not be significant 2) CFI and TLI should be more than 0.920 3) RMSEA should be less than 0.070, and 4) SRMR should be less than 0.080. Results from CFA indicated fit model $(\square 2=56.182, \mathrm{p}$-value $=.057, \mathrm{df}=41, \mathrm{RMSEA}=0.030, \mathrm{CFI}=0.988, \mathrm{TLI}$ $=0.981$, and SRMR $=0.044)($ See Figure 1$)$

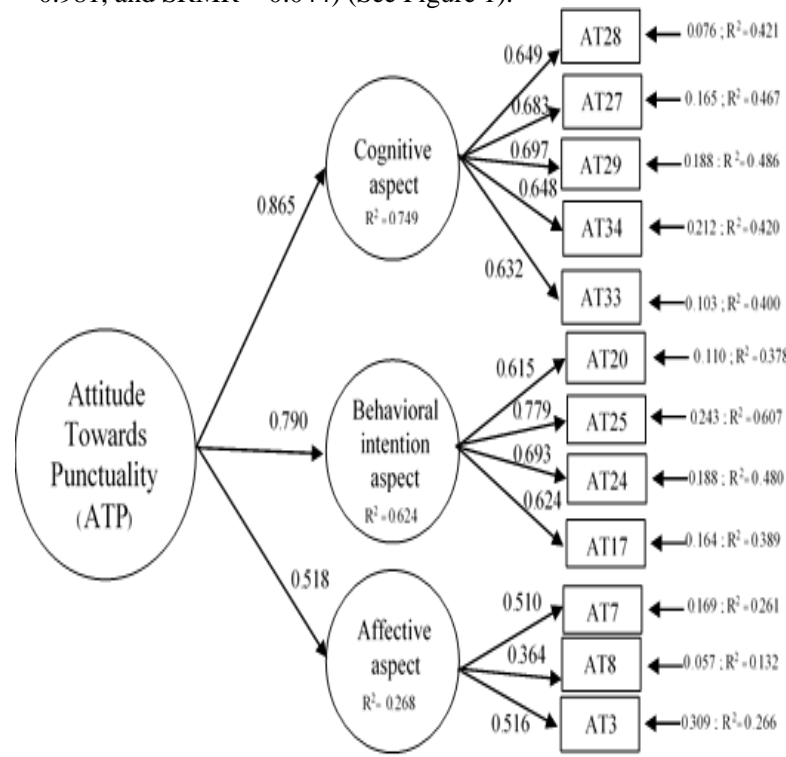

Fig. 1 Second-order confirmatory factor analysis of Attitude Towards Punctuality (ATP)

\subsection{Study 4: Reliability And Validity}

In this step, reliability and validity of ATP were considered. Data were from the last group of 225 university students. The reliability of the ATP score with 12 items was 0.796 . The score reliability showed good interitem response relatedness. The value 0.796 was a psychometric property of the group of 225 students who responded to the 12-item measure of ATP when they were in their classes. Therefore, when the ATP scale is used elsewhere, reliability of the scores has to be computed and reported again 18 .

In addition, alpha reliability of the sample scores on cognitive factor, behavioral intention factor, and affective factor were 0.724 , 0.655 , and 0.537 , respectively.

Three measures were used to validate ATP as follows. First, core self-evaluation (CSE) 8 consisted of 4 dimensions: general self-efficacy, locus of control, neuroticism, and self-esteem. The total of 12 items yielded the score reliability of 0.600 . The CFA confirmed this measurement model $(\square 2=48.143$, p-value $=$ $0.0686, \mathrm{df}=35, \mathrm{RMSEA}=0.041, \mathrm{CFI}=0.975 ; \mathrm{TLI}=0.952$, SRMR $=0.059)$. Second, future time perspective $(F T P) 6,19$ consisted of two factors: 1) positive future perspective reflecting in planning for the future, and preparing for desirable future outcomes (with 5 items), and 2) low hedonic present perspective reflecting little bad feeling when meet with non-punctuality, and less preference of joy and happiness rather than being on time and success in the future (with 10 items). The score reliability of 15 items was 0.561 . The CFA confirmed this measurement model $(\square 2=97.494, \mathrm{p}$-value $=0.0775, \mathrm{df}=79, \mathrm{RMSEA}=0.032, \mathrm{CFI}=$ 0.947; TLI $=0.929$, SRMR $=0.064)$. Third, punctual behavior (PB)20 referred to three dimensions as punctual class attendance and meeting deadline for assignments, being early for appointments and group meetings, and being recognized as punctual person. The score reliability of this measure with 13 items was 0.856 The CFA confirmed this measurement model $(\square 2=69.051$, pvalue $=0.0569, \mathrm{df}=52, \mathrm{RMSEA}=0.029, \mathrm{CFI}=0.999 ; \mathrm{TLI}=$ $0.986, \mathrm{SRMR}=0.031)$. The descriptive statistics of these variables are in Table 1 .

Table 1 Descriptive statistics of the variables for validation

\begin{tabular}{|c|c|c|c|c|}
\hline Statistics & CSE & FTP & ATP & PB \\
\hline No. of items & 12 & 15 & 12 & 13 \\
\hline Mean & 49.582 & 54.947 & 58.520 & 58.182 \\
\hline Median & 49.000 & 55.000 & 59.000 & 59.000 \\
\hline SD & 5.304 & 6.759 & 7.469 & 9.570 \\
\hline Skewness & 0.040 & 0.372 & -0.202 & -0.188 \\
\hline SE. of Skewness & 0.162 & 0.162 & 0.162 & 0.162 \\
\hline Kurtosis & 0.028 & 0.546 & -0.430 & -0.215 \\
\hline SE. of Kurtosis & 0.323 & 0.323 & 0.323 & 0.323 \\
\hline Minimum & 34.000 & 40.000 & 37.000 & 29.000 \\
\hline Maximum & 64.000 & 78.000 & 72.000 & 78.000 \\
\hline Score reliability & 0.600 & 0.561 & 0.796 & 0.856 \\
\hline
\end{tabular}

Results from Table 2 revealed that CSE, FTP, and PB were positively and significantly related to ATP.

Table 2 Intercorrelation of variables

\begin{tabular}{|c|c|c|c|c|c|c|}
\hline Variables & Mean & SD & 1 & 2 & 3 & 4 \\
\hline 1. CSE & 49.582 & 5.304 & 1 & & & \\
\hline 2. FTP & 54.947 & 6.759 & $.357^{* *}$ & 1 & & \\
\hline 3. ATP & 58.520 & 7.469 & $.256^{* *}$ & $.289^{* *}$ & 1 & \\
\hline 4. PB & 58.182 & 9.570 & $.315^{* *}$ & $.244^{* *}$ & $.596^{* *}$ & 1 \\
\hline
\end{tabular}

Note: $* \mathrm{p}<.05, * * \mathrm{p}<.01 . \mathrm{CSE}=$ Core self-evaluation, FTP $=$ Future time

perspective, $\mathrm{ATP}=$ Attitude towards punctuality, $\mathrm{PB}=$

Punctual behavior.

In addition, in this study, two other personality variables (CSE and FTP) also were positively related to punctual behavior $(\mathrm{r}=$ 0.315 , and 0.244 , respectively). While they also were found to be positively related to attitudes (ATP) at about the same magnitudes $(\mathrm{r}=0.256$, and 0.289 , respectively). Furthermore, CSE and FTP were also positively related $(\mathrm{r}=0.357)($ Table 2$)$.

By performing Hierarchical Multiple Regression Analysis, 
using CSE and FTP in step 1, and ATP in step 2 as independent variables to predict PB (Table 3), it was found that in the first step, CSE and FTP (Beta $=.261$ and .151 , respectively) together could predict PB for $11.900 \%$. In step 2, ATP (Beta $=.546)$ could predict $\mathrm{PB}$ beyond these two predictors in step 1 for $26.500 \%$ which could add up the predictive power of PB to $38.400 \%$.

Table 3 Hierarchical Multiple Regression for PB

\begin{tabular}{|c|c|c|c|c|}
\hline Step & $\mathrm{R}^{2}\left(\mathrm{Adj}^{2}\right)$ & $\Delta \mathrm{F}(\mathrm{sig})$ & Beta & $\mathrm{B}(\mathrm{SE})$ \\
\hline Step1 & & & & \\
\hline FTP & $11.900(11.100)$ & $14.994(.000)$ & 0.151 & $0.214(.095)$ \\
\hline CSE & & & 0.261 & $0.470(.122)$ \\
\hline Step 2 & & & & \\
\hline ATP & $38.400(37.600)$ & $95.104(.000)$ & 0.546 & $0.699(.072)$ \\
\hline & $\left(\Delta \mathrm{R}^{2}=26.500\right)$ & & & \\
\hline
\end{tabular}

Note: CSE $=$ Core self-evaluation, FTP $=$ Future time perspective, $\mathrm{ATP}=$ Attitude towards punctuality, $\mathrm{PB}=$ Punctual behavior.

\section{Discussion}

The present research article aimed at responding to the need for positive measure of attitude toward punctuality (ATP) for use with undergraduate students in Thailand. The newly constructed scale, resulting from performing exploratory, as well as, confirmatory factor analyses, was validated by two well-known psychological tests (CSE and FTP, the latter was a short-form of CFC).

The criterion-related validation of the ATP scale scores of 225 students was further explored by a newly constructed measure of punctual behavior (PB). Both the ATP scale (of 12 items with 3 factors) and the $\mathrm{PB}$ measure (of 13 items with 3 factors) possessed high score reliability (Table 1 ). The incremental validity of ATP test score showed that the ATP could predict the PB by 26.500 percents beyond that of the CSE and FTP test scores, with the total of 38.400 percents. Thus, more predictors of PB should be added. However, the above results can be interpreted as successful construct of the ATP scale.

As for the indicators of punctuality, the present study found that the correlation of ATP and PB was rather high $(r=0.596)$. It is not surprising to find that attitudes and behavior (measured the same context) can be moderately to highly

related5. The revealed structure of attitude towards punctuality can be used as a basis for attitude intervention as follows. The results in Figure 1 showed that the cognitive aspect and the behavioral intention aspect were strong contributors to ATP than the affective aspect. Therefore, the intervention model for promoting attitude towards academic punctuality in Thai students should first emphasize the various benefits and the important aspects of being socially punctual.

In addition, positive intention to increase punctual habits must be enhanced. Furthermore, the affective-content items were one third of the attitude items (4 items out of the total of 12 items) Thus, good feeling about and self-reinforcement for being punctual, should also be included in the training.

Punctuality in this study was measured by self-report of the students. The measures of both attitudes and behavior are called "summated rating method" which has more strength than limitations when constructed with rigorous practice. Punctuality at workplace can be measured more objectively, usually by registered time machine or by the time gap of the actual time and the scheduled time for bus operators 21 , or other working personnel. However, when appropriate objective indicators are not available or not practical, self-reported measures such as the one in this study can be acceptable.

The relationships between time perspective in terms of future orientation and self-control with punctual behavior were found to have strong support from many intervention studies22-23. Selfmanagement, which is the second part of future perspective, when was emphasized in the training of government employees could result in punctual work-time practice. At a 6 and 9 month follow up, punctual work behaviors were still present with an increase in self-efficacy22. Afterwards, a meta analytical study reported a new intervention model for college performance and retention. Robbin, Oh, Le and Button23 found that most interventions (organizational and educational) showed both direct and indirect effects on the targeted performance and retention. The important mediators were motivational, emotional, and social factors. Academic skills and self-management were among the most effective interventions. In other words, both psychological factors and desirable behaviors should be enhanced 23 .

Furthermore, Both FTP and CSE seemed to be important antecedents of attitude and punctual behavior (Table 3). Therefore, FTP, CSE, and attitudes should be pursued further. Interaction effects among personal and situational factors on punctual behavior with different definitions should be included in the future studies. Situational factors can be, for example, types of persons, such as friends vs. instructors, types of activities such as academic meeting vs. dinner party.

Interaction effects of both personal and situational factors on all types of behavior, as well as direct effects, have been proposed in a famous interactional model by Endler and Magnusson24 in 1976. This model has great and widespread influence in various studies of behavioral antecedents. The theory of planned behavior (TPB) 25 can be considered as one of the theories in this paradigm. This TPB theory emphasizes attitudes and social norm with addition of perceived behavioral

control, as predictors of intention to action, especially in college students25. Thus, TPB theory had been used as basis for constructing many intervention programs, especially for health behaviors. However, at least two studies26-27 reported that interventions could not lead to behavior change. Only increase in knowledge, attitudes and perceived behavioral control of the recipients were found.

On the other hand, in 362 college students aged 18 to 25 years at a public university in Macao, China, the three variables in the TPB theory mentioned above were found to be positively related to healthy sleep of these students. Furthermore, perceived invulnerability were important antecedents of all of the components in TPB theory, as revealed by path analysis 28 .

Parental nurturance (love and reasoning orientated practices) was one of the most important experience factors having strong effects on many important psychological characteristics, as well as various desirable behavior in Thai school and college students 29-30.

Among the psychological characteristics found in relations to positive child-rearing practices were belief in internal locus of control (IC), and future orientation and self-control (FOSC), as well as, good mental health, happiness and psychological immunity29-30. In addition, the above mentioned, child rearing practices and the psychological characteristics, such as IC, CSE, and FOSC, were found to be highly reported in Thai university students as positively related to rule-abiding behavoir31, and desirable health behaviors 32 .

\section{Limitations and Implications}

This study also had some limitations, namely, (1) the four variables used in this study were measured with the same method of 6unit rating scales, (2) the four measures were self-reported, and (3) correlations could not be interpreted as causations. Therefore, some positive relationships among the variables could be inflated. Table 1 also showed that the CSE and FTP had lower score reliabilities ( 0.600 and 0.561 , respectively). While, the two Thai scales (ATP and PB) had satisfactory score reliabilities (0.796 and 0.856 , respectively). These results lead to suggestion that measurement invariance of the CSE and the FTP should be available, or else, the correlations with other variables may be less interpretable 33. The CFA results revealed that the CSE and the FTP models were confirmed in Thai sample in this study. Thus, these two foreign scales were partly suitable for use with Thai students. 


\section{Conclusions}

The present research evidences and related findings point to the fact that the newly constructed attitude scale (ATP) has satisfactory qualifications in terms of score reliability and criterion-related validity. This attitude scale scores were positively related to but still independent of punctual behavior (PB). The two scales can be used with confidence in future studies and intervention projects. The present findings also offer the confirmation that academic punctual behavior of Thai university students can be enhanced by the three psychological characteristics. However, it is recommended that experimental

studies should be carried out to confirm this assertion.

In addition, punctual behavior should be explored further. More important antecedents from both situational factors, as well as, personal factors and their interaction effects can strengthen the punctuality theory. Academic punctuality as desirable and positive habits can also reduce academic procrastination. The two areas of research should be incorporated to yield a more fruitful research area and a brighter future for "what works" interventions.

\section{Acknowledgments}

This article is a part of research project "A study of development and validation of psycho-moral strength measures in consonant with Thai undergraduate students' qualifications" under the umbrella of research plan "Psycho-moral strength in research and training of lecturers for students' development" which was financially supported by the Annual Government Statement of Expenditure Year 2017. Researchers also would like to thank National Institute of Development Administration (NIDA) for additional other financial and infrastructural supports.

\section{References and Notes}

[1] W.P. Dabale, and T. Masese, Euro. J. Busi. \& Soc. Sci, 3, 9 (2014)

[2] A.A. Mamum, S.F.F. Shasudin, N.B.C. Nawi, N.A.B. Nasi, and M.N.B. Zakaria, Adv.

[3] Sci. Lett., 23, 9 (2017)

[4] P.A. Alexander, H. Fives, M.M. Buehl, and J. Mulhern, Teach. \& Teach. Edu., 18, 7

[5] (2002).

[6] S. Marcellia, and D. Hamfri, Ad. Sci. Lett., 23, 9 (2017).

[7] M. Fishbein, and I. Ajzen, Belief, Attitude, Intention, and Behavior: An Introduction

[8] to Theory and Research, Addison-Wesley, Reading (1975).

[9] P.G. Zimbardo, K.A. Keough, and J.N. Boyd, Per. \& Ind. Dif., 23 6 (1997).

[10] C.H. Chang, D.L. Ferris, R.E. Johnson, C.C. Rosen, and J.A. Tan, J Mana., 38, 1

[11] (2012).।

[12] T.A. Judge, A Erez, J. Bono, and C J. Thoresen, Pers. Psy, 56, 2 (2003).

[13] I M. Putrawan, Adv. Sci. Lett., 23,9 (2017)

[14] W.J. Popham, Phi Delta Kappan, 74, 7 (1993).

[15] D. Bhanthumnavin, NIDA Dev. J., 39, 1 (1999).

[16] L.T. White, R. Valk, and A. Dialmy, J. Cross-Cul. Psy., 42, 3 (2011).

[17] L.J. Cronback, and G. Geser, Psychological Testing and Personnel Decision,

[18] Univ. of Illinois, Campaign.

[19] G.T. Smith, S. Fischer, and S.M. Fister, Psy. Ass, 15, 4 (2003).

[20] J. H. McMillan, and S. Schumacher, Research in Education. A Conceptual

[21] Introduction (5th ed.). Longman, New York (2001)

[22] J. C. Nunnally, Psychometric Theory. McGraw-Hill, New York (1967).

[23] J.F. Hair, W.C. Black, B.J. Babin, and R.E. Anderson, Multivariate Data Analysis.

[24] (7th Edition), Pearson, New York (2010).

[25] C.E. Green, C.E. Chen, J.E. Helms, and K.T.Henze, Psy. Ass, 23,3 (2011)
[26] N.Y.F. Siu, H.H.Y. Lam, J.J.Y. Le, and A.M. Przepiorka, Acta Psy., 151, 0 (2014).

[27] B. Sorod, and D. Bhanthumnavin, A study of development and validation of psycho-moral strength measures in consonant with Thai undergraduate students' qualifications (Research report), Nat. Inst. Dev. Adm., Bangkok, Thailand (in progress).

[28] N.Yaakub, and M. Napiah, Int. J. Civ.\& Env. Eng, 5, 12 (2011).

[29] G. Latham, and C.A. Frayne, J. Appl. Psy.,74, 3 (1989).

[30] S.B. Robbins, I.S. Oh, H. Le, and C. Button, J. Appl. Psy., 64, 5 (2009).

[31] S.Endler, and Magnusson, Psy. Bull, 83, 5 (1976).

[32] I.Ajzen, Heal. Psy. Rev., 9, 2 (2014).

[33] E.J. Kothe, B.A. Mullan, and P. Butow, Appetite, 58, (2012).

[34] B. Mullan, and C. Wong, Food Cont., 21, 11 (2010).

[35] H.C.F. Lao, V.Y.K. Tao, and A.M.S.Wu, Aus. J. of Psy, 68, 1 (2016).

[36] D. Bhanthumnavin, Antecedents and consequences of mindful risktaking behavior

[37] in secondary school students (Research report). National Research Council of Thailand (2013)

[38] D. Bhanthumnavin, Antecedents of readiness and potentiality to become

[39] researchers in different types of individuals: Undergraduate students

[40] (Research report). National Institute of Development Administration, Thailand

[41] (2015).

[42] N. Chodsusanae, Psycho-social correlates of ecotourist behavior in university

[43] students (Master Thesis). National Institute of Development Administration,

[44] Thailand (2002).

[45] B. Praneetvatakul, Psychosocial as correlates of communicable disease preventive

[46] behavior in daily life of undergraduate students (Master Thesis). National Institute of Development Administration, Thailand (2002).

[47] M. Ziegler, and D. Bensch, Euro. J. of Psy. Asses., 29, 2 (2013).

Appendix:

Attitude Towards Punctuality Scale (12 items)

AT28 The person who comes on time is rather stupid because (s)he knows that waiting for other is inevitable. (Cog -)

AT27 When going for a special lecture, one can come at any time, punctuality is not necessary. (Cog -)

AT29 I have no anxiety even though I came late at task group meeting. (Aff -)

AT34 If I have to rent a room, I expect to often receive notice for late payment. (Cog -)

AT33 If I have to go to a special lecture, I usually go slowly without hurry (Int -)

AT20 I usually have no feeling even when a friend comment about my failure to keep an appointment. (Aff -)

AT25 I am a simple and relaxed person so I have less intention to be on time. (Int - )

AT24 Even though, I am usually late for appointment with my friends, I do not intent to do better. (Int -)

AT17 I think that if I arrive late for group work, it is not that important. (Cog -)

AT7 If I can be on time to myself, I will feel proud of it. (Aff

$+)$

AT8 I am pleased to be able to work according to the schedule. $($ Aff +$)$

AT3 I believe that self-training to be punctual in studying is important for my future work life. $(\mathrm{Cog}+)$

This summated rating scale, each item accompanied with 6-unit rating ranges from $1=$ "not true at all" to $6=$ "Extremely true". Negative worded items are first 8 items, must be reversed the scores. 